\title{
Die richtige
}

\section{Diagnose kann über}

\section{Leben und Tod}

\section{entscheiden.}

\section{Auch wirtschaftlich!}

Machen Sie sich die tägliche Praxis einfacher.

Verlassen Sie sich auf professionelle Unterstützung in

- Praxisgründung • Praxisführung • Praxisübergabe/-übernahme • Praxisfinanzierungen und Finanzplanung

- Persönliche Risiko- und Altersvorsorge • Praxis-, Sach- und Berufshaftpflichtversicherungen • Optimierte

Steuerplanung $\bullet$ Nachfolgeplanung und -regelung • Unternehmenswertberechnungen/Praxisverkauf

- Praxis- und Stellenvermittlung • Seminare zu Themen wie Praxiseröffnung/-übernahme, Praxisübergabe,

Finanz- und Steuerplanung, EDV • Stellenmarkt unter www.fmhjob.ch • Praxismarkt unter www.fmhprax.ch

- Factoring・Inkasso

FMH Consulting Services

Burghöhe 1 • Postfach 246 • 6208 Oberkirch

Telefon $0419250077 \cdot$ Fax 0419210586

mail@fmhconsulting.ch • www.fmhconsulting.ch 